\title{
Potential Risks of Poaceous Plants as Infectious Sources of Rice Black-Streaked Dwarf Virus Transmitted by the Small Brown Planthopper, Laodelphax striatellus
}

\author{
Keiichiro Matsukura, ${ }^{\dagger}$ Sachiyo Sanada-Morimura, Tomohisa Fujii, and Masaya Matsumura \\ National Agricultural Research Organization Kyushu Okinawa Agricultural Research Center, Kumamoto 861-1192, Japan
}

\begin{abstract}
The recent reemergence of rice black-streaked dwarf virus (RBSDV) has caused severe rice yield losses in several areas of East Asia. To identify the most important infectious sources of RBSDV, we compared the susceptibility of major poaceous plants to RBSDV infection and survival and the RBSDV acquisition efficiency of a vector insect, the small brown planthopper Laodelphax striatellus. RBSDV infection and survival rates of L. striatellus were significantly high in wheat (Triticum aestivum 'Norin61') and rice (Oryza sativa 'Reiho'), indicating that these crops can be important sources of RBSDV. Our results also showed that

(Lolium multiflorum 'Hataaoba') and L. striatellus. These results indicate that control of RBSDV and $L$. striatellus on winter-spring crops of wheat and Italian ryegrass may avoid an RBSDV epidemic on rice during the following summer. In addition to infections of wheat and Italian ryegrass, RBSDV infections were detected in Avena fatua, Avena sterilis subsp. ludoviciana, Cynosurus echinatus, Festuca arundinacea, Festuca pratensis, Lolium perenne, and Vulpia myuros var. megalura, although the infection efficiency varied.
\end{abstract} RBSDV can complete its infection cycle between Italian ryegrass
Keywords: Fijivirus, long-distance migration, RT-qPCR,
Virus transmission as well as feeding injury by three rice planthoppers, the brown planthopper Nilaparvata lugens Stål, the whitebacked planthopper Sogatella furcifera Horváth, and the small brown planthopper Laodelphax striatellus Fallén, are serious threats to stable rice production in East and Southeast Asia. Outbreaks of rice striped virus (RSV) transmitted by $L$. striatellus have been a threat to rice production in East Asian countries since around 2000 (Lee et al. 2008; Shiba et al. 2018; Wang et al. 2008). Southern rice black-streaked dwarf virus (SRBSDV) is transmitted exclusively by S. furcifera (Zhou et al. 2008) and has quickly expanded from southeast China to a wide distribution range from northern Vietnam to western Japan since it first detection in 2001 (Cuong et al. 2009; Matsukura et al. 2013). The epidemics of these viral diseases across a broad region of East and Southeast Asia are caused by longdistance migration of the vector planthoppers (Matsukura et al. 2017; Otuka et al. 2010). Development and improvement of the control strategies for the rice viruses mediated by the migratory planthoppers are urgent issues for stable rice production in East Asia.

Rice black-streaked dwarf virus (RBSDV) is an important rice virus belonging to the genus Fijivirus. This virus is transmitted by L. striatellus, Unkanodes sapporonus Matsumura, and Unkanodes albifascia Matsumura to several poaceous plants, including rice, maize, wheat, and barley (Shinkai 1962). RBSDV is transmitted by L. striatellus in a persistent, propagative manner (Hibino 1996), and it is close to maize rough dwarf virus in having common and/or similar characteristics in host range (Milne and Lovisolo 1977; Shinkai 1962), vector insects (Hibino 1996; Vidano 1970), and RNA sequences (Wang et al.

Current address of author K. Matsukura: Institute of Agrobiological Sciences, National Agricultural Research Organization, Ibaraki 305-8634, Japan.

${ }^{\dagger}$ Corresponding author: K. Matsukura; mtkr@affrc.go.jp

Funding: This study was supported by research project "Development of mitigation and adaptation technologies to climate change in the sectors of agriculture, forestry, and fisheries" grant 11130 from the Ministry of Agriculture, Forestry, and Fisheries of Japan.

The author(s) declare no conflict of interest.

Accepted for publication 12 December 2018.

() 2019 The American Phytopathological Society
2003). After the serious epidemic of RBSDV in East Asia from the 1950s to 1970s (Hibino 1996), no serious outbreaks were reported until the end of the 1990s. During the last two decades, however, reemergence of RBSDV has occurred in several areas of East Asia. After the late 1990s, severe epidemics of RBSDV were reported in several areas of China (Bai et al. 2002). In South Korea, the range of RBSDV epidemics expanded after 2000 (Lee et al. 2005). Also, in Japan, RBSDV occurrence on rice began to increase in Saitama Prefecture after 2010.

The recent reemergence of RBSDV and RSV in East Asia is caused by increased occurrence of $L$. striatellus in this region. Both viruses are transmitted mainly by this planthopper to several poaceous plants, including rice, in a persistent-propagative manner (Hibino 1996); however, unlike RSV, RBSDV is not transmitted transovarially from adult female to offspring. Furthermore, typical symptoms of rice infected with these viruses are different. Rice plant infected with RSV shows yellowed and drooping leaves at late tilling stage. However, RBSDV-infected rice shows stunted growth with upheaving of leaf veins and twisting of leaf tips. These two viruses can be acquired by L. striatellus simultaneously, at least under laboratory conditions, although influence of the double infection on virus transmission efficiency is not clear (Li et al. 2010). Several ecological factors, such as the development of insecticide resistance in $L$. striatellus (Gao et al. 2008; Sanada-Morimura et al. 2011), efficient virus transfer along with long-distance migration of $L$. striatellus (Otuka et al. 2010; Sun et al. 2015), changes in cropping systems (Yoshida et al. 2014), and perhaps, recent global warming (Yamamura and Yokozawa 2002), are pointed out as promoting recent outbreaks of L. striatellus in East Asia.

Characterization of the RBSDV infection cycle, particularly between host plants and the vector $L$. striatellus, is important for evaluating the risk of RBSDV epidemics and establishing efficient control strategies for this viral disease. Several poaceous plants are known to be hosts of both RBSDV and L. striatellus (Mochida and Okada 1971; Shinkai 1962), yet the key infectious source of RBSDV leading to epidemics on rice has not yet been identified. In this study, we examined several biological traits related to the efficiency of RBSDV transmission to several poaceous plants under laboratory condition, which will provide the risk potentials of major poaceous crops and plants as infectious sources of this virus.

\section{Materials and Methods}

Virus and insect used. Symptomatic rice plants infected with RBSDV were collected in an experimental field at Saitama 
Agricultural Technology Research Center in Kumagaya City, Saitama Prefecture, Japan $\left(36^{\circ} 10^{\prime} 09^{\prime \prime}\right.$ N, $139^{\circ} 21^{\prime} 14^{\prime \prime}$ E) on 8 September 2017 and taken to the laboratory, where they were maintained in a phytotron at $23^{\circ} \mathrm{C}$ under a 16 -h light/8-h dark photoperiod. RBSDV infection of each plant was confirmed with reverse transcription polymerase chain reaction (RT-PCR) followed by gel electrophoresis using two RBSDV-specific primer pairs: S9f1 and S9r1 for the partial sequence of the p9-1 gene and S10f3 and S10r3 for partial sequences of the outer capsid protein gene (Bai et al. 2002).

A laboratory-reared strain of L. striatellus originally collected in Ogori City, Fukuoka Prefecture, Japan $\left(33^{\circ} 22^{\prime} 34^{\prime \prime}\right.$ N, $130^{\circ} 32^{\prime} 29^{\prime \prime}$ E) on 8 October 2015 was used in this study. Only RSV-free L. striatellus confirmed by enzyme-linked immunosorbent assay (ELISA) (Omura et al. 1986) were used as progenitors of the strain to avoid the possible influence of RSV infestation on the acquisition and transmission of RBSDV in L. striatellus. The insects were mass reared on rice (Oryza sativa 'Reiho') at $25^{\circ} \mathrm{C}$ under a 16-h light/8-h dark photoperiod as described in a previous report (SanadaMorimura et al. 2013).

Poaceous crop and plant hosts tested. Three poaceous crops (rice, wheat [Triticum aestivum 'Norin61'], and Italian ryegrass [Lolium multiflorum 'Hataaoba']) and 13 poaceous plants (Agrostis alba, Avena fatua, Avena sterilis subsp. ludoviciana, Briza maxima, Cynosurus echinatus, Festuca arundinacea, Festuca pratensis, Lolium multiflorum [wild type], Lolium perenne, Poa annua, Poa pratensis, Vulpia myuros var. megalura, and Bromus catharticus) were used in this investigation. Seeds of each species/cultivar were sown in a plastic dish (150-ml volume) with soil (Hinokunitokotsuchi) and maintained at $25^{\circ} \mathrm{C}$ and $\sim 70 \%$ relative humidity under a 16-h light/8-h dark photoperiod. For A. fatua and A. sterilis, seeds were placed in a petri dish with filter paper and $12 \mathrm{ml}$ of gibberellin solution $(0.05 \% \mathrm{wt} / \mathrm{vol})$ for 6 days before seeding to promote germination. After germination, each seed was transplanted into a 200-ml plastic cup containing soil. At 14 days after transplanting, young plants were used in the virus infection test described below.

RBSDV infection test. First and second instar nymphs of $L$. striatellus were used for the virus infection tests. Plants were individually covered by an acrylic cylinder with a nylon cloth placed over the top to provide ventilation for the insects and plants. Because $L$. striatellus requires an $\sim 5$-day acquisition period followed by a $>20$-day latent period to become viruliferous ( $\mathrm{Li}$ et al. 2010; Miao et al. 2014), the plants were kept at $20^{\circ} \mathrm{C}$ during the virus acquisition period to suppress development of $L$. striatellus. At 14 days after release, when L. striatellus had grown to the old nymph and early adult stages, the viruliferous $L$. striatellus were transferred to 2 -week-old poaceous plants for virus inoculation. The RBSDV acquisition rate of the viruliferous $L$. striatellus was determined the above-described RT-PCR method ( $n=40$ adults).

Viruliferous L. striatellus were released on the poaceous crops and plants at a density of two insects per plant. Plants were individually covered by an acrylic cylinder with a nylon cloth covering the top, and they were held for 46 days at $25^{\circ} \mathrm{C}$ under a 16 -h light/8-h dark photoperiod. After the RBSDV inoculation period, RBSDV infection of each plant was examined using the reverse transcription quantitative polymerase chain reaction (RT-qPCR) method described below. Fifteen plants were tested for all species except $B$. maxima and $V$. myuros var. megalura, of which five plants were tested owing to low germination rates and/or poor development.

RBSDV detection with RT-qPCR. Presence of an outer capsid protein gene of RBSDV in each plant was examined with RT-qPCR, because this method is generally more sensitive than the other diagnosis methods, such as gel electrophoresis and ELISA. The primer pairs F3 (5'-CCC CAG AGA CTT TCC GAT AC-3') and B3 (5'-GGT CTT TAA GTT GCG TGA TGT-3') developed for RBSDV-specific detection with reverse transcription loop-mediated isothermal amplification (RT-LAMP) (Le et al. 2010) were used for our RT-qPCR method. Total RNA was extracted following a method described for the quantification of SRBSDV (Matsukura et al. 2013). Briefly, sampled leaves were weighed and then crushed in a mixture of $250 \mu \mathrm{l}$ of TriPure Isolation Reagent (Roche Diagnostics Co., Ltd.) and $50 \mu \mathrm{l}$ of chloroform. Purified total RNA from each plant was dissolved in $50 \mu \mathrm{l}$ of diethylpyrocarbonate-treated water (Nippon Gene Co., Ltd.) and used as a template for RT-qPCR.

RT-qPCR was conducted with a Lightcycler 480FLM (Roche Diagnostics Co., Ltd.) using a One Step SYBR PrimeScript RT-PCR Kit II (Takara Bio Inc.). Each reaction contained $5 \mu$ l of $2 \times$ One Step SYBR RT-PCR Buffer 4, $0.4 \mu 1$ of PrimeScript 1step Enzyme Mix 2, $0.8 \mu \mathrm{l}$ of a mixture of $\mathrm{F} 3$ and $\mathrm{B} 3$ primers ( $10 \mu \mathrm{M}$ each), $2 \mu \mathrm{l}$ of template RNA, and $1.8 \mu \mathrm{l}$ of RNase-free $\mathrm{dH}_{2} \mathrm{O}$. Thermal conditions were 1 cycle of reverse transcription $\left(42^{\circ} \mathrm{C}\right.$ for $5 \mathrm{~min}$ and $95^{\circ} \mathrm{C}$ for $\left.10 \mathrm{~s}\right), 35$ cycles of amplification $\left(95^{\circ} \mathrm{C}\right.$ for $10 \mathrm{~s}, 60^{\circ} \mathrm{C}$ for $10 \mathrm{~s}$, and $74^{\circ} \mathrm{C}$ for 15 $\mathrm{s}), 1$ cycle of melting curve analysis $\left(95^{\circ} \mathrm{C}\right.$ for $5 \mathrm{~s}, 65^{\circ} \mathrm{C}$ for $1 \mathrm{~min}$, and $97^{\circ} \mathrm{C}$, with increment rates of $0.11^{\circ} \mathrm{C}$ per $1 \mathrm{~s}$ ), and cooling $\left(40^{\circ} \mathrm{C}\right.$ for $\left.30 \mathrm{~s}\right)$. Using a dilution series of RNA extracted from RBSDV-infected rice, the primer efficiency was estimated to be 1.928 , with Cycle threshold $(\mathrm{Ct})$ values ranging between 10 and 30 . No proper melting curve was observed for samples with $\mathrm{Ct}$ values $>30$; therefore, samples with $\mathrm{Ct}$ values $>30$ were regarded as negative (i.e., no infection of RBSDV).

Nymph survival test on poaceous plants. The survival of L. striatellus nymphs on RBSDV-free poaceous plants was examined. Twenty first and second instar nymphs were released on each plant at 60 days after transplanting the germinated seeds. Each plant was covered by an acrylic cylinder with a nylon cloth covering the top and maintained at $23^{\circ} \mathrm{C}$ under a $16-\mathrm{h}$ light/8-h dark photoperiod. At 10 days after releasing the nymphs, the number of surviving L. striatellus was counted. Of 16 poaceous plants used in the infection test, A. fatua, F. pratensis, L. multiflorum, P. pratensis, and $V$. myuros var. megalura were not used in this test because of poor development of these plants. Tests were replicated on five test plants of each species (i.e., 20 nymphs $\times$ five replicates).

RBSDV acquisition test from poaceous plants. Two plants each of RBSDV-infected rice, wheat, Italian ryegrass, and $L$. multiflorum (wild type) and one plant of RBSDV-infected L. perenne were used for the RBSDV acquisition test. These RBSDV-infected plants were those produced in the RBSDV infection test. Forty first and second instar nymphs of $L$. striatellus were released on individual plants covered by nylon cloth-covered acrylic cylinders and kept at $20^{\circ} \mathrm{C}$ for 5 days. After the virus acquisition period, nymphs were transferred to RBSDV-free rice seedlings and held at $20^{\circ} \mathrm{C}$ for 9 days. This additional incubation period on RBSDV-free rice avoided the high mortality on unfavorable host plants for L. striatellus and detection of RBSDV from the digestive tracts of nonviruliferous $L$. striatellus. The numbers of survived $L$. striatellus on each plant were from 6 to 26 . After extracting total RNA from these survived $L$. striatellus, RBSDV acquisition was tested with the RT-qPCR method described above.

Statistical analyses. The RBSDV infection efficiency among poaceous plants and the RBSDV acquisition efficiency by $L$. striatellus among RBSDV-infected plants were tested with a $\chi^{2}$ test followed by residual analysis as a post hoc test. Differences in survival rates of $L$. striatellus among poaceous plants were tested with analysis of variance (ANOVA) followed by Tukey's honestly significant difference (HSD) test after arcsine transformation of the survival rates. All statistical analyses were performed with $\mathrm{R}$ version 3.3.2 (R Core Team 2016).

\section{Results}

Susceptibility to RBSDV in poaceous plants. The RBSDV acquisition efficiency of released $L$. striatellus in the infection test was $95 \%(n=40)$, suggesting that at least one viruliferous nymph fed on most tested plants. The RBSDV infection efficiency significantly differed among the tested poaceous plants $\left(\chi^{2}\right.$ test, $\chi^{2}=$ 55.19 , degree of freedom $(\mathrm{df})=15, P<0.001)$. The subsequent residual analysis test showed significantly higher infection efficiency in rice, wheat, and $L$. multiflorum. No infection of RBSDV was observed on A. alba, P. annua, P. pratensis, B. catharticus, and B. maxima (Table 1). Wheat had the highest RBSDV infection efficiency.

Nymphal survival on RBSDV-free poaceous plants. The survival rate of $L$. striatellus nymphs significantly differed among the 11 tested poaceous plants (ANOVA after arcsine transformation, $F=21.60$, df $=10, P<0.001) ;>80 \%$ of the nymphs survived on both rice and wheat, a level that is significantly higher than that on 
cannot infect $A$. alba and $B$. catharticus but can infect $L$. perenne (Shinkai 1962). L. perenne is a perennial plant closely related to Italian ryegrass (L. multiflorum), and it is often grown as a pasture grass in cold areas within temperate regions (Wilkins 1991). The persistency of RBSDV on $L$. perenne should be examined to determine if this plant is an important infectious source of RBSDV for several years after infected. Our data showed that RBSDV infects both $F$. arundinacea and $F$. pratensis, plants that were previously reported to be nonhosts of RBSDV (Shinkai 1962). This result is not surprising, because the genus Festuca is close to the genus Lolium in the phylogeny of the tribe Poeae (Gillespie et al. 2008). However, RBSDV infection on $P$. annua was reported by Shinkai (1962), although no RBSDV infection by this plant was observed in our study (Table 1). P. annua is an important winter-spring host for L. striatellus (Yoshida et al. 2014); therefore, this plant can be an important host of RBSDV.

Controlling vector insects is a general strategy in the management of plant viral diseases mediated by insects. Control of $L$. striatellus from winter to spring by removing host plants, such as residual rice and poaceous weeds, has been promoted in Japan for many years (Shiba et al. 2016; Yoshida et al. 2014). The relatively higher importance of winter-spring crops (i.e., wheat and Italian ryegrass) as infectious sources of RBSDV as implied in this study suggests a need for additional vector control in these crop fields. Application of effective insecticides for L. striatellus (Gao et al. 2008; Sanada-Morimura et al. 2011) would suppress densities of RBSDV-viruliferous insects and/or RBSDV-infected plants in wheat fields when concerned about an epidemic of RBSDV. Several RBSDV diagnostic methods, such as ELISA (Wang et al. 2006), RT-PCR (Bai et al. 2002), RTLAMP (Le et al. 2010), and RT-qPCR (Zhang et al. 2013 and this study), will help to monitor potential RBSDV epidemics in winterspring crops. There is no realistic way to control L. striatellus in Italian ryegrass fields at present, but the use of symbiotic fungal endophytes or other biocontrol agents on Italian ryegrass is a promising strategy for controlling these insect pests (Matsukura et al. 2012).

\section{Acknowledgments}

We thank Dr. Mitsuru Okuda for providing plant seeds and valuable suggestions for our study and Dr. Kazuhiko Sakai for providing information about RBSDV occurrence in Saitama Prefecture, Japan and RBSDV-infected rice. We also thank all members of the Insect Pest Management Group of National Agricultural Research Organization Kyushu Okinawa Agricultural Research Center for maintaining and preparing the virus and insect strains used in this study.

\section{Literature Cited}

Bai, F.-W., Yan, J., Qu, Z.-C., Zhang, H.-W., Xu, J., Ye, M.-M., and Shen, D.-L. 2002. Phylogenetic analysis reveals that a dwarfing disease on different cereal crops in China is due to Rice black streaked dwarf virus (RBSDV). Virus Genes 25:201-206

Cuong, H. V., Hai, N. V., Man, V. T., and Matsumoto, M. 2009. Rice dwarf disease in North Vietnam in 2009 is cause by southern rice black-streaked dwarf virus (SRBSDV). Bull. Inst. Trop. Agric. Kyushu Univ. 32:85-92.

Fujii, T., Hori, M., and Matsuda, K. 2010. Attractants for rice leaf bug, Trigonotylus caelestialium (Kirkaldy), are emitted from flowering rice panicles. J. Chem. Ecol. 36:999-1005.

Gao, B., Wu, J., Huang, S., Mu, L., and Han, Z. 2008. Insecticide resistance in field populations of Laodelphax striatellus Fallén (Homoptera: Delphacidae) in China and its possible mechanisms. Int. J. Pest Manage. 54:13-19.

Gillespie, L. J., Soreng, R. J., Bull, R. D., Jacobs, S. W. L., and Refulio-Rodriguez, N. F. 2008. Phylogenetic relationship in subtribe Poinae (Poaceae, Poeae) based on nuclear ITS and plastid trnT-trnL-trnF sequences. Botany 86:938-967.

Hibino, H. 1996. Biology and epidemiology of rice viruses. Annu. Rev. Phytopathol. 34:249-274

Ishii, Y., Mukhtar, M., Idota, S., and Fukuyama, K. 2005. Rotational grazing system for beef cows on dwarf napiergrass pasture oversown with Italian ryegrass for 2 years after establishment. Grassl. Sci. 51:223-234.

Le, D. T., Netsu, O., Uehara-Ichiki, T., Shimizu, T., Choi, I.-R., Omura, T., and Sasaya, T. 2010. Molecular detection of nine rice viruses by a reverse-transcription loopmediated isothermal amplification assay. J. Virol. Methods 170:90-93.

Lee, B. C., Hong, Y. K., Hong, S. J., Park, S. T., and Lee, K. W. 2005. Occurrence and detection of Rice black-streaked dwarf virus in Korea. Plant Pathol. J. 21:172-173.

Lee, B. C., Yoon, Y. N., Hong, S. J., Hong, Y. K., Kwak, D. Y., Lee, J. H., Yae, U. S., Kang, H. W., and Hwang, H. G. 2008. Analysis of the occurrence of Rice stripe virus. Res. Plant Dis. 14:210-213.
Li, L., Li, H., Dong, H., Wang, X., and Zhou, G. 2010. Transmission by Laodelphax striatellus Fallen of Rice black-streaked dwarf virus from frozen infected rice leaves to healthy plants of rice and maize. J. Phytopathol. 159:1-5.

Matsukura, K., Matsumura, M., Takeuchi, H., Endo, N., and Tokuda, M. 2009 Distribution, host plants, and seasonal occurrence of the maize orange leafhopper, Cicadulina bipunctata (Melichar) (Homoptera: Cicadellidae), in Japan. Appl. Entomol. Zool. (Jpn.) 44:207-214.

Matsukura, K., Shiba, T., Sasaki, T., and Matsumura, M. 2012. Enhanced resistance to four species of clypeorrhynchan pests in Neotyphodium uncinatum infected Italian ryegrass. J. Econ. Entomol. 105:129-134.

Matsukura, K., Towata, T., Sakai, J., Onuki, M., Okuda, M., and Matsumura, M. 2013. Dynamics of Southern rice black-streaked dwarf virus in rice and implication for virus acquisition. Phytopathology 103:509-512.

Matsukura, K., Towata, T., Yoshida, K., Sakai, J., Okuda, M., Onuki, M., and Matsumura, M. 2015. Quantitative analysis of Southern rice black-streaked dwarf virus in Sogatella furcifera and virus threshold for transmission. Phytopathology 105:550-554.

Matsukura, K., Watanabe, T., and Matsumura, M. 2017. An epidemic model of a rice virus transmitted by a migratory planthopper. J. Pest Sci. 90:669-682.

Miao, H.-Q., Di, D.-P., Zhang, A.-H., Lu, Y.-G., Tian, L.-Z., Stewart, L. R., and Redinbaugh, M. G. 2014. Efficient inoculation of Rice black-streaked dwarf virus to maize using Laodelphax striatellus Fallen. J. Phytopathol. 163: 529-535.

Milne, R. G., and Lovisolo, O. 1977. Maize rough dwarf virus and related viruses. Adv. Virus Res. 21:267-341.

Mochida, O., and Okada, T. 1971. A list of Delphacidae (Homoptera) in Japan with special reference to host plants, transmission of plant diseases, and natural enemies. Bull. Kyushu Agric. Exp. Stn. 15:737-843.

Nagasawa, A., Takahashi, A., and Higuchi, H. 2012. Host plant use for oviposition by Trigonotylus caelestialium (Hemiptera: Miridae) and Stenotus rubrovittatus (Hemiptera: Miridae). Appl. Entomol. Zool. (Jpn.) 47:331-339.

Nakano, H., Morita, S., Hattori, I., and Sato, K. 2008. Effects of planting time and cultivar on dry matter yield and estimated total digestible nutrient content of forage rice in southwestern Japan. Field Crops Res. 105:116-123.

Omura, T., Takahashi, Y., Shohara, K., Minobe, Y., Tsuchizaki, T., and Nozu, Y. 1986. Production of monoclonal antibodies against Rice stripe virus for the detection of virus antigen in infected plants and viruliferous insects. Ann. Phytopathol. Soc. Jpn. 52:270-277.

Otuka, A., Matsumura, M., Sanada-Morimura, S., Takeuchi, H., Watanabe, T., Ohtsu, R., and Inoue, H. 2010. The 2008 overseas mass migration of the small brown planthopper, Laodelphax striatellus, and subsequent outbreak of rice stripe disease in western Japan. Appl. Entomol. Zool. (Jpn.) 45 259-266.

R Core Team. 2016. R: A Language and Environment for Statistical Computing. R Foundation for Statistical Computing, Vienna, Austria.

Sakamoto, T., Nguyen, N. V., Ohno, H., Ishitsuka, N., and Yokozawa, M. 2006 Spatio-temporal distribution of rice phenology and cropping systems in the Mekong Delta with special reference to the seasonal water flow of the Mekong and Bassac rivers. Remote Sens. Environ. 100:1-16.

Sanada-Morimura, S., Matsumura, M., and Noda, H. 2013. Male killing caused by a Spriroplasma symbiont in the small brown planthopper, Laodelphax striatellus. J. Hered. 104:821-829.

Sanada-Morimura, S., Sakumoto, S., Ohtsu, R., Otuka, A., Huang, S.-H., Thanh, D. V., and Matsumura, M. 2011. Current status of insecticide resistance in the small brown planthopper, Laodelphax striatellus, in Japan, Taiwan, and Vietnam. Appl. Entomol. Zool. (Jpn.) 46:65-73.

Seo, S. 2005. Forage production and animal husbandry in Korea. Grassl. Sci. 51:21-25.

Shiba, T., Hirae, M., Hayano-Saito, Y., Ohto, Y., Uematsu, H., Sugiyama, A., and Okuda, M. 2018. Spread and yield loss mechanisms of rice stripe disease in rice paddies. Field Crops Res. 217:211-217.

Shiba, T., Hirae, M., Hayano-Saito, Y., Uematsu, H., Sasaya, T., Higuchi, H., Ohto, Y., and Okuda, M. 2016. Seasonal changes in the percentage of Rice stripe virus Viruliferous Laodelphax striatellus (Hemiptera: Delphacidae) in Paddy Fields in Japan. J. Econ. Entomol. 109:1041-1046.

Shinkai, A. 1962. Studies on the insect transmission of rice virus diseases. Rep Nat. Agr. Sci. C-14:1-112.

Sun, J.-T., Wang, M.-M., Zhang, Y.-K., Chapuis, M.-P., Jiang, X.-Y., Hu, G., Yang, X.-M., Ge, C., Xue, X.-F., and Hong, X.-Y. 2015. Evidence for high dispersal ability and mito-nuclear discordance in the small brown planthopper, Laodelphax striatellus. Sci. Rep. 5:8045.

Vidano, C. 1970. Phase of Maize rough dwarf virus multiplication in the vector Laodelphax striatellus (Fallén). Virology 41:218-232.

Wang, H. D., Chen, J. P., Wang, A. G., Jiang, X. H., and Adams, M. J. 2009. Studies on the epidemiology and yield losses from rice black-streaked dwarf disease in a recent epidemic in Zhejiang province, China. Plant Pathol. 58. 815-825.

Wang, H. D., Chen, J. P., Zhang, H. M., Sun, X. L., Zhu, J. L., Wang, A. G., Sheng, W. X., and Adams, M. J. 2008. Recent rice stripe virus epidemics in Zhejiang Province, China, and experiments on sowing date, disease yield loss relationships, and seedling susceptibility. Plant Dis. 92: 1190-1196. 
Wang, Z.-H., Fang, S.-G., Xu, J.-L., Sun, L.-Y., Li, D.-W., and Yu, J.-L. 2003. Sequence analysis of the complete genome of Rice black-streaked dwarf virus isolated from maize with rough dwarf disease. Virus Genes 27:163-168.

Wang, Z.-H., Fang, S.-G., Zhang, Z.-Y., Han, C.-G., Li, D.-W., and Yu, J.-L. 2006. Development of an ID-ELISA for the detection of Rice black-streaked dwarf virus in plants. J. Virol. Methods 134:61-65.

Wilkins, P. W. 1991. Breeding perennial ryegrass for agriculture. Euphytica 52: 201-214.

Yamamura, K., and Yokozawa, M. 2002. Prediction of a geographical shift in the prevalence of rice stripe virus disease transmitted by the small brown planthopper, Laodelphax striatellus (Fallén) (Hemiptera: Delphacidae), under global warming. Appl. Entomol. Zool. (Jpn.) 37:181-190.
Yoshida, K., Matsukura, K., Sakai, J., Onuki, M., Sanada-Morimura, S., Towata, T., and Matsumura, M. 2014. Seasonal occurrence of Laodelphax striatellus (Hemiptera: Delphacidae) in rice-forage crops mixed cropping area in central Kyushu, Japan. Appl. Entomol. Zool. (Jpn.) 49:475-481.

Zhang, P., Mar, T. T., Liu, W., Li, L., and Wang, X. 2013. Simultaneous detection and differentiation of Rice black streaked dwarf virus (RBSDV) and Southern rice black streaked dwarf virus (SRBSDV) by duplex real time RT-PCR. Virol. J. 10:24.

Zhou, G., Wen, J., Cai, D., Li, P., Xu, D., and Zhang, S. 2008. Southern rice blackstreaked dwarf virus: A new proposed Fijivirus species in the family Reoviridae. Chin. Sci. Bull. 53:3677-3685. 